\title{
Flow Measurements Using Particle Image Velocimetry in the Ultracompact Combustor
}

\author{
Levi M. Thomas, Richard D. Branam, and Mark F. Reeder \\ Department of Aeronautics, Air Force Institute of Technology-AFIT/ENY, \\ Wright-Patterson AFB, 2950 Hobson Way, Building 640, Dayton, OH 45433, USA \\ Correspondence should be addressed to Mark F. Reeder, mark.reeder@afit.edu
}

Received 26 August 2011; Accepted 8 November 2011

Academic Editor: Roger L. Davis

Copyright ( 92012 Levi M. Thomas et al. This is an open access article distributed under the Creative Commons Attribution License, which permits unrestricted use, distribution, and reproduction in any medium, provided the original work is properly cited.

\begin{abstract}
The potential for the ultracompact combustor (UCC) lie in future research to reduced fuel consumption and improved engine performance. Velocity measurements performed on the UCC test rig at the Air Force Institute of Technology revealed flow patterns and time-averaged turbulence statistics for data taken burning hydrogen fuel in a straight and a curved cavity vane configuration. Over an equivalence ratio from 0.7 to 1.5 , the straight vane configuration showed spanwise velocity decreased linearly with distance from the cavity vane over the width of the main channel. Increasing the flow rates and holding the equivalence ratio and ratio of cavity to main airflow rates constant, flow velocities in the main channel showed an increase with the curved circumferential configuration but a decrease with the straight circumferential configuration. Turbulence intensity is expected to be a major contributing factor, specifically since measured at $15 \%$ and $21 \%$ in the main channel for the straight and curved configurations, respectively. The results also show how the radial vane cavity (RVC) created strong vorticity throughout the main flow supporting a recirculation zone for mixing. Peak vorticity occurred farthest from the cavity vane suggesting the angle of the radial vane cavity is effective in generating increasing flow rotation.
\end{abstract}

\section{Introduction}

The concept of an ultracompact combustor (UCC) has been in development for over ten years, offering the potential advantages of increasing gas turbine engine (GTE) performance while decreasing overall length and weight as described in [1-3]. Enabled by its short axial length, a UCC could be used in a GTE in place of the conventional main burner, as an interturbine burner, or both. Instead of using the axial length between the compressor and turbine, the UCC uses a channel around the engine's circumference for the primary combustion zone (Figure 1). The combustion reaction is cavity-stabilized using trapped vortex combustion (TVC) along the outer wall of the circumferential flow path. By utilizing the circumference of the engine to complete the primary combustion, studies have shown the combustor section of a GTE could be shortened by $66 \%$ while maintaining $99 \%$ combustion efficiency [4].
Specific thrust, a measure of thrust per unit air mass flow, of modern GTEs, is primarily limited by the maximum allowable turbine inlet temperature [6]. As GTE main combustors operate lean overall, burning additional fuel will raise the turbine inlet temperature resulting in increased thermal energy which can then be extracted by the turbine to drive a larger fan or increase the exhaust velocity. However, increasing $\mathrm{T}_{t 4}$ would further exacerbate an already demanding thermal management issue in the high-pressure turbine. An interturbine burner creates some of the same benefits of increasing turbine inlet temperature by burning additional fuel to reheat the flow after the high-pressure turbine has extracted much of the thermal energy. Currently, interturbine burners are limited to ground-based GTEs due to their size and weight. Developing the UCC for use in a gas turbine engine offers the potential benefits of lower engine weight, shorter length, higher specific thrust, and lower thrust-specific fuel consumption [1]. 


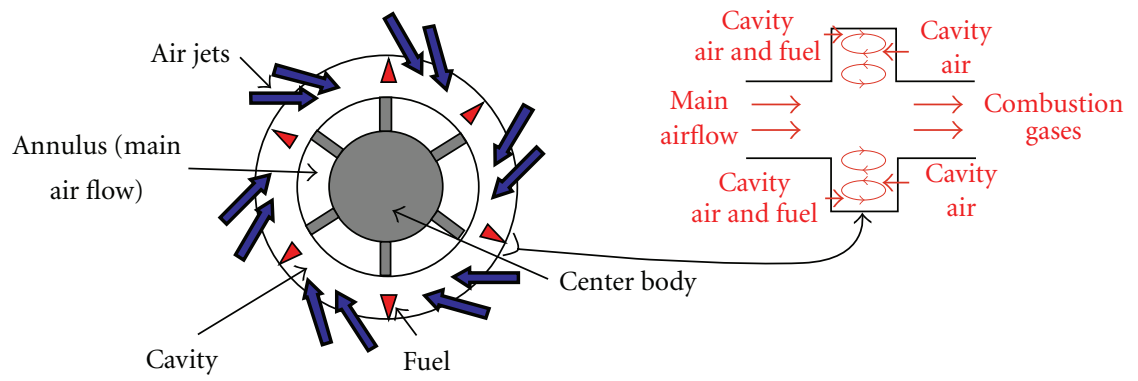

(a)

(b)

FIgURE 1: Cross-section of (a) UCC pictorial concept and (b) trapped vortex combustion [5].

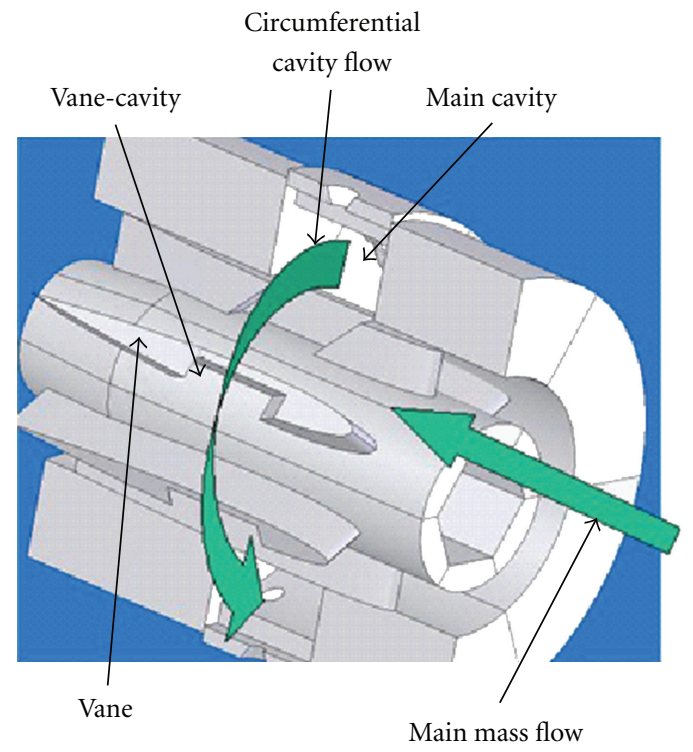

(a)

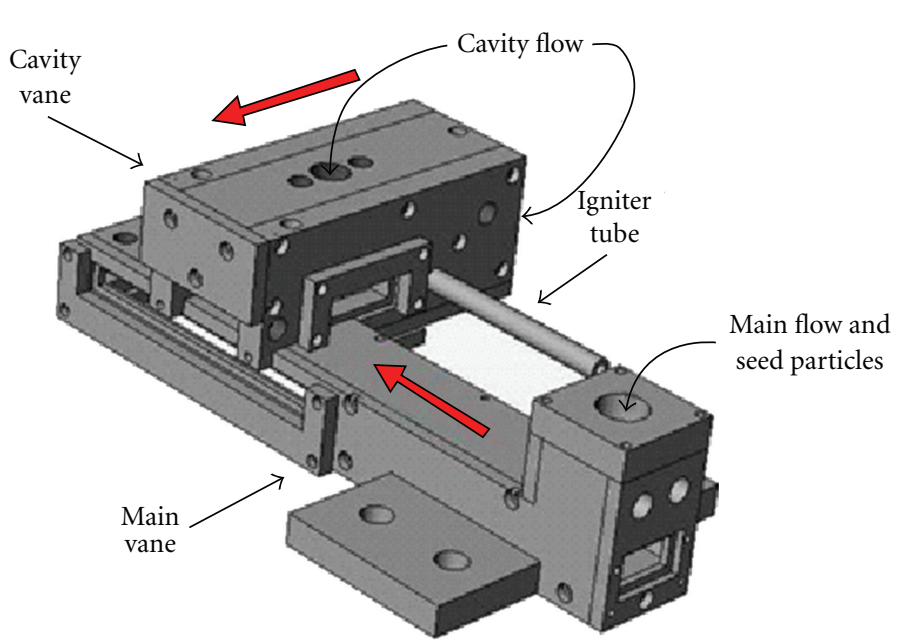

(b)

FIgURE 2: Comparison of (a) a full model UCC concept and (b) the sector model of a straight cavity configuration [7].

\section{Background and Objectives}

In order to develop the UCC concept into a working design suitable for use in a GTE, the Air Force Institute of Technology (AFIT) designed and built a small-scale model representing a one sixth sector of the UCC [8]. The sector rig was built primarily to investigate the interaction between the primary (axial) and cavity (circumferential) flow paths and the radial vane cavity (RVC). The flow pattern is depicted schematically in Figure 1(a). In the left image, the crosssection including the cavity is viewed from the front of the engine, and the main flow in the annulus, as depicted, would be directed into the page. In this representation, combustion is envisioned to take place inside the cavity. Ideally, the hot low-density gaseous products of combustion would propagate inward, toward the main flow while the cooler higher-density reactants would tend to remain within the circumferential cavity. This flow pattern, which is generally consistent with a situation where buoyancy forces are dominant, would be advantageous in that residence times for the fuel-air mixture would be long, allowing for complete combustion. However, many questions remain about what type of mixing occurs at the interface between the cavity and the main flow (i.e., are the dominant forces buoyancy or baroclinicity?). If appreciable amounts of unburned fuel were to exit the cavity prematurely, engine efficiency would drop and any perceived advantage of the UCC design would be lost. The flow pattern near the interface of the circumferential cavity and the main flow is quite complex even for a nonreacting flow, let alone for a combustion environment where rotor blade passage induces unsteady flow. For example, Figure 1(b) depicts a possible vortex pattern normal to the circumferential flow direction in the cavity itself.

This present study is devoted to illuminating the velocity field near the interface of the circumferential cavity and the main flow, albeit for a simplified geometry. Here the proposed geometry of the UCC placed in a gas turbine engine, shown in Figure 2(a), is contrasted to a model used in the current investigation, shown in Figure 2(b). One of the most obvious differences is that the cavity flow sector model studied here is composed of a straight, rather than curved, 


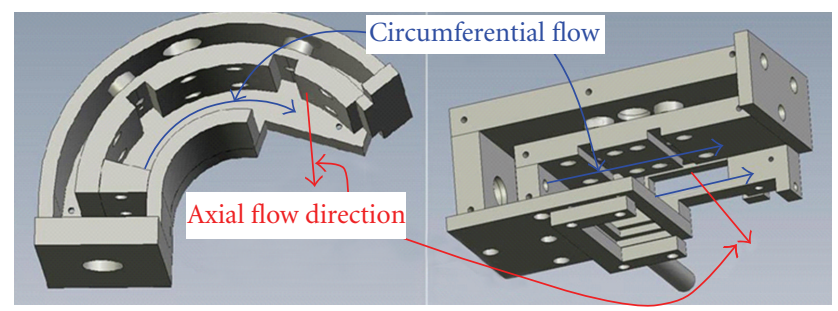

Figure 3: Showing the curved combustion channel versus the straight combustion channel, indicated circumferential flow is the primary flame zone.

section. The flow field may generally be characterized by the main flow and the cavity flow, as depicted in Figure 2(b). The model has two entrances and two exits, one each for the main flow and the cavity flow. As depicted in Figure 2(b) the main flow passes below the cavity flow, and each follows an unimpeded path from just upstream of their interface to their respective exits. Combustion is brought about by igniting a fuel-air mixture in the cavity flow, within a flame holder (labeled Igniter Tube in the figure), upstream of the interface. The main flow, laden with seed particles used for PIV, passes through a ninety degree turn just upstream of the interface in order to accommodate a quartz window, allowing the laser sheet to propagate through the main flow channel. The turn in the flow is several hydraulic diameters upstream of the vane allowing for essentially uniform flow at the leading edge of the vane.

An important issue is how the curvature of the cavity flow influences mixing of combustion products, investigated by using two different circumferential channels. Figure 3 illustrates the two channels used in testing. The curved channel (left) and straight (right) cavity flow sections, each attach to the same main flow channel represented in Figure 2(b). One underlying hypothesis of the UCC is buoyancy, and baroclinicity will drive combustion products toward the centerline, which here is described as the main flow. The main goal of this experiment was to compare and contrast results acquired for the circumferential channels shown in Figure 3. To accomplish this task, it was necessary to establish similar conditions while incorporating combustion in each case.

Using the circumference of the engine for the primary combustion zone offers the benefit of greatly reducing the axial length. However, a subsequent technical challenge is the exhaust products moving around the circumferential channel must be reintroduced into the axial flow channel at angles approaching 90 degrees. The flow interaction between the main axial flow channel and the circumferential cavity channel is the focus of this experiment. This region of interest is shown in the dotted red box in Figure 4. Much of the research conducted on the AFIT sector rig up to this point has involved laser diagnostic techniques for which there are several quartz windows allowing optical access. Previous research has used laser-induced fluorescence (LIF) to measure temperatures and species concentrations within the combustor. This research used particle image velocimetry
(PIV) to measure velocity-fields over several 2-D planes at the intersection of the main flow and circumferential flow channels directly over the radial vane cavity.

The PIV technique uses digital image correlation to measure average particle displacements over a set time thereby obtaining a first order velocity approximation. One can estimate particle displacement by visually examining an interrogation region from two corresponding image pairs as shown on the right side of Figure 5. The particles in the first image appear to have shifted to the left in the second image. Cross-correlation determines the average shift from one image to the next, and with knowledge of the elapsed time between the first and second images, an average velocity is estimated for each interrogation region.

\section{Experimental Facility and Methodology}

The PIV instrumentation consisted of a computer running dynamic studio for data acquisition and processing, a Flowsense $4 \mathrm{M}$ camera with a $2048 \times 2048$ pixel CCD and 8-bit data resolution, a New Wave Solo 200XT Nd: YAG Qswitched laser, a train of sheet-forming optics, a Scitek PS10 powder seeder to inject the silicon carbide tracer particles into the flow, and two Newport linear translation devices to move the experimental plane within the combustor (Figure 6) [9]. Particles were approximately one micron in diameter, and the seeder is equipped with sonic jets which create high shear flow fields to ensure that the powder does not agglomerate while being dispensed in the outlet chamber [10]. Given the low subsonic conditions in the test section, the particle sizing and density of the particles injected into the flow field followed established guidelines to ensure the particles accurately represented velocity vectors, specifically within the turbulence levels experienced in this experiment. Further details of particle size choice and particle density can be found in [9].

The laser was formed from a beam into a vertically divergent sheet using a half-cylindrical lens followed by a planoconvex lens focusing the sheet thickness. Mirrors were used to position the beam, the last of which was mounted on a linear translator (Figure 7).

The final mirror in the optics train and the camera are mounted on translation devices to allow the experimental plane to be swept through the width of the UCC's main channel. The width of the focused laser sheet allowed for four distinct experimental planes with relative positions shown in Figure 8. The left graphic in Figure 8 shows the viewing direction of the camera capturing the PIV data through the window. The window on the main channel also enables viewing of the airfoil shape of the vane and the channel within the vane. The configuration shown is for the curved cavity flow channel, and data is captured in the planes just above the radial vane cavity as seen through the window in this representation. The graphic on the right of Figure 8 shows the test chamber turned so the direction of view is in the upward direction on the page. The graphic shows the location of the four laser sheets, as they would be perpendicular to the airfoil vane and parallel to the window. The measurement planes (green) are centered at 3, 6, 9, and 


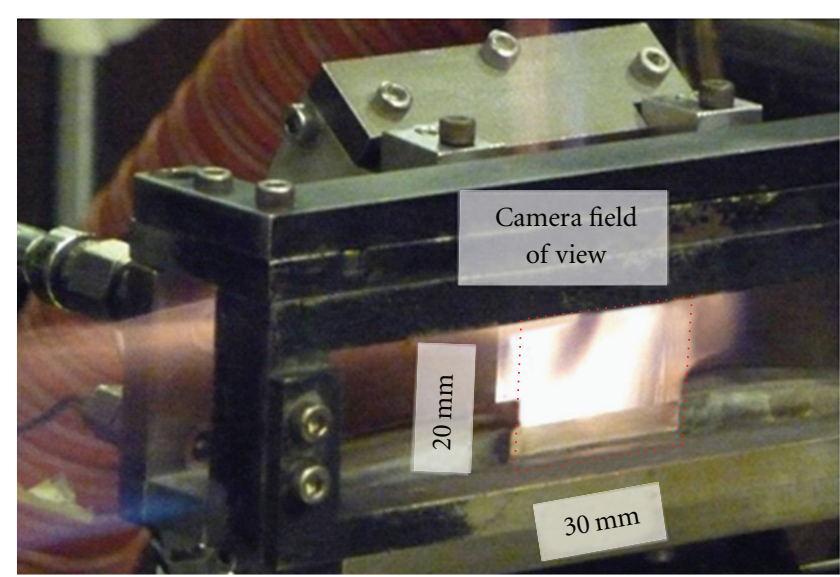

(a)

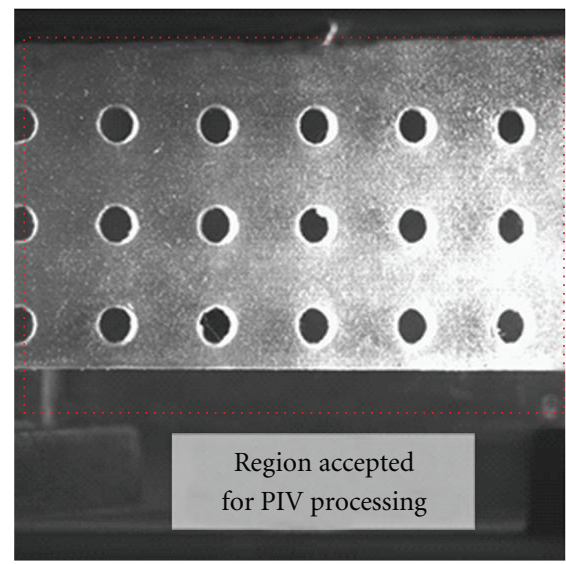

(b)

FIGURE 4: Approximate camera field of view on the UCC (a); calibration image showing region of image used for PIV processing (b).

12 millimeters as measured from the combustion chamber (curved channel). The total width of the main channel is $14.3 \mathrm{~mm}$.

The experimental factors investigated were (1) the main channel air mass flow, (2) the cavity channel air mass flow, (3) the cavity channel equivalence ratio, (4) cavity vane curvature, and (5) the position of the experimental plane within the main vane. Keeping with previously identified optimal flow rates and ratios $[2,11]$, four ratios of main to cavity mass flow rates were chosen as: $20: 1,10: 1,7.5: 1$, and $5: 1$. These correspond to cavity mass flow of $5 \%, 10 \%$, $15 \%$, and $20 \%$ of the main channel mass flow, respectively. Four equivalence ratios were chosen for the hydrogen fuel and air flow in the circumferential channel: $\phi=0.7,1.0$, 1.3, and 1.5. Hydrogen is chosen as the fuel for this test campaign to specifically target one of the major theorems of this research, the effects of the density gradient. The lighter fuel and resulting exhaust helps reinforce these effects.

Table 1 summarizes the test matrix for the first of the two experiments focusing on the ratio of mass flow in the main channel compared to the circumferential channel as well as the circumferential channel equivalence ratio. The second experiment focused on increasing mass flow while keeping the equivalence ratio constant at $\Phi=1.0$ and the ratio of mass flows constant at 0.1 (10\% cavity flow relative to the main flow), see Table 2 .

In order to process the acquired image pairs, each image is broken up into interrogation regions for crosscorrelation. Larger interrogation regions will contain more tracer particles and raise the signal-to-noise ratio, while smaller interrogation regions allow for a higher sampling resolution. $64 \times 64$ pixel interrogation regions were used with $50 \%$ overlap for the cross-correlation processing. A "No-DC" filter was applied to eliminate any signal corresponding to zero displacement from frame one to frame two. A Gaussian window function (1) (Figure 9) was also used to apply a higher weight to signals in the center of the interrogation region and less weight to those near the boundaries which inherently experience higher noise mainly
TABLE 1: Test matrix for cavity to main channel flow rate ratio and equivalence ratio study.

\begin{tabular}{lcccc}
\hline \multicolumn{5}{c}{ Test matrix: ratio of flow rates } \\
\hline Cavity equivalence (-) & 0.7 & 1 & 1.3 & 1.5 \\
Hydrogen flow (SLPM) & 30 & 30 & 30 & 30 \\
Cavity airflow (kg/min) & 0.13 & 0.09 & 0.07 & 0.06 \\
\hline Ratio of cavity to main airflow & \multicolumn{5}{c}{ Main airflow $(\mathrm{kg} / \mathrm{min})$} \\
\hline 0.2 & 0.66 & 0.46 & 0.35 & 0.31 \\
0.15 & 0.88 & 0.61 & 0.47 & 0.41 \\
0.1 & 1.31 & 0.92 & 0.71 & 0.61 \\
0.05 & 2.63 & 1.84 & 1.41 & 1.23 \\
\hline
\end{tabular}

TABLE 2: Test matrix for velocity study.

\begin{tabular}{lcc}
\hline \multicolumn{3}{c}{ Test matrix: mass flow increase } \\
\hline $\begin{array}{l}\text { Cavity equivalence ratio: } 1.0 \\
\text { Ratio of cavity to main air: } 0.1\end{array}$ & & \\
\hline Main airflow $(\mathrm{kg} / \mathrm{min})$ & $\begin{array}{c}\text { Cavity airflow } \\
(\mathrm{kg} / \mathrm{min})\end{array}$ & $\begin{array}{c}\text { Hydrogen flow } \\
(\text { SLPM })\end{array}$ \\
\hline 0.61 & 0.06 & 20 \\
0.92 & 0.09 & 30 \\
1.23 & 0.12 & 40 \\
1.53 & 0.15 & 50 \\
\hline
\end{tabular}

due to loss-of-pairs from the movement between frames one and two.

Gaussian window function:

$$
W(m, n)=\exp \left[-\left[\frac{1}{k}\right]^{2}\left(\left(\frac{2 m}{M}\right)^{2}+\left(\frac{2 n}{N}\right)^{2}\right)\right] .
$$

In the window weighting function defined in the figure above: $(m, n)$ is pixel position, $(M, N)$ is the size of the interrogation region which is $(64,64)$, and " $k$ " (used to determine the strength of the weighting) is 1.19 .

The Solo 200XT has two lasers sharing a common exit path enabling two pulses to be released within $0.5 \mu \mathrm{s}$ at 


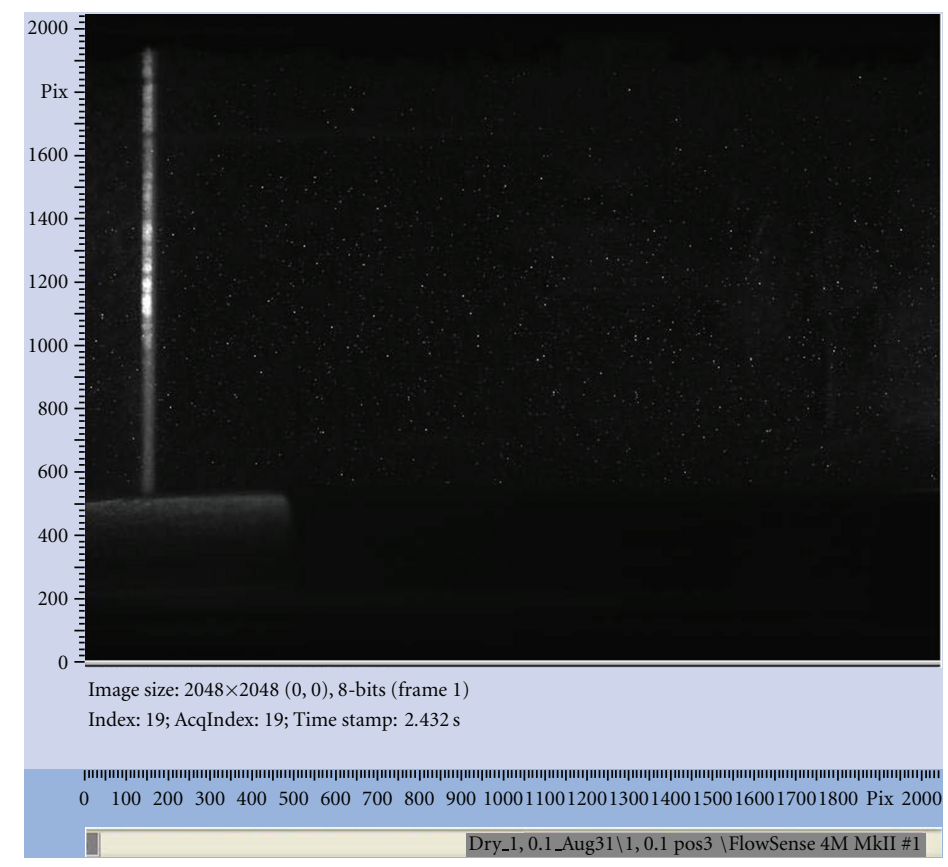

(a)

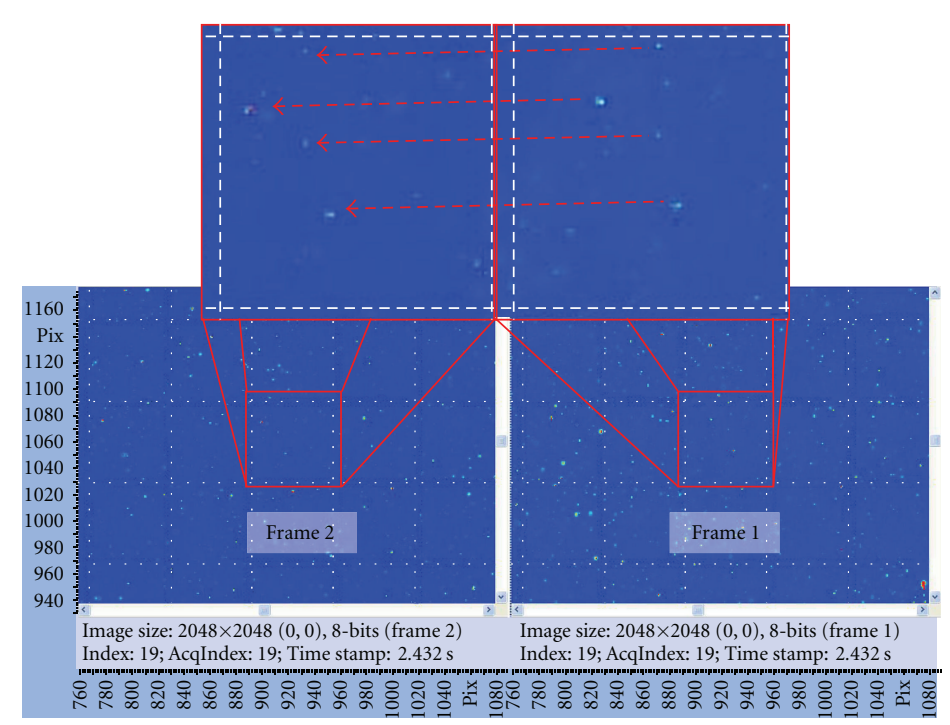

(b)

FIGURE 5: Raw data image (a); zoomed-in and color-enhanced view of corresponding interrogation regions from frames 1 and 2 showing particle displacement (b).

a maximum rate of $7.4 \mathrm{~Hz}$. This relatively short-pulse delay makes it well suited for PIV applications. The pulse delay was varied from 3.0 to $8.0 \mu$ s to keep the seed particle displacement under one quarter of the interrogation region size. As the $64 \times 64$ pixel interrogation regions corresponded to approximately $1 \times 1 \mathrm{~mm}$, the particle displacements being measured to estimate velocity were less than $0.25 \mathrm{~mm}$. The maximum dual laser pulse repetition frequency of $7.4 \mathrm{~Hz}$ was used, and a minimum of 50 image pairs were collected for data processing at each test condition.
The thermocouples, pressure transducers, and mass flow controller used to meter the hydrogen flow have accuracy tolerances that were relatively low compared to the overall variability in main air and secondary air mass flows. The fuel mass flow controller is specifically calibrated for hydrogen. As the ratio between these two mass flows was one of the primary experimental factors under investigation, an airflow variability study was performed by setting the airflows at each of the test conditions, allowing 30 seconds to steady, and then recording the variability over the next 30 seconds. 


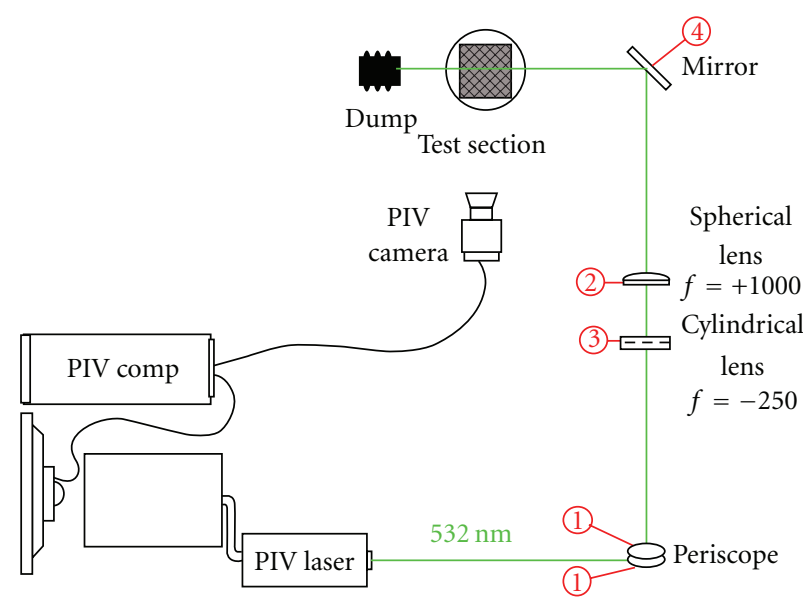

(a)

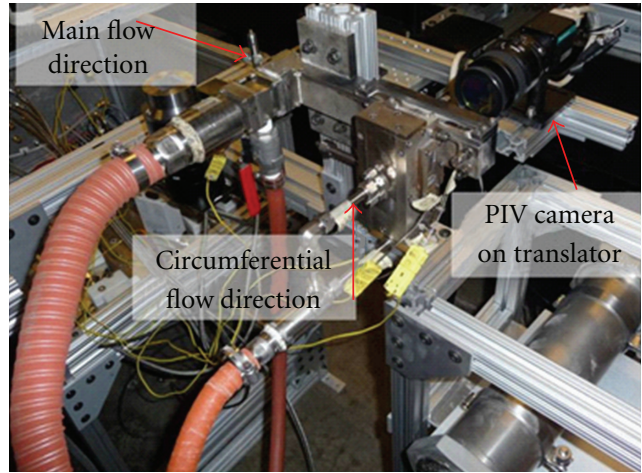

(b)

FIGURE 6: Diagram of PIV experimental setup (a); UCC sector rig (b).

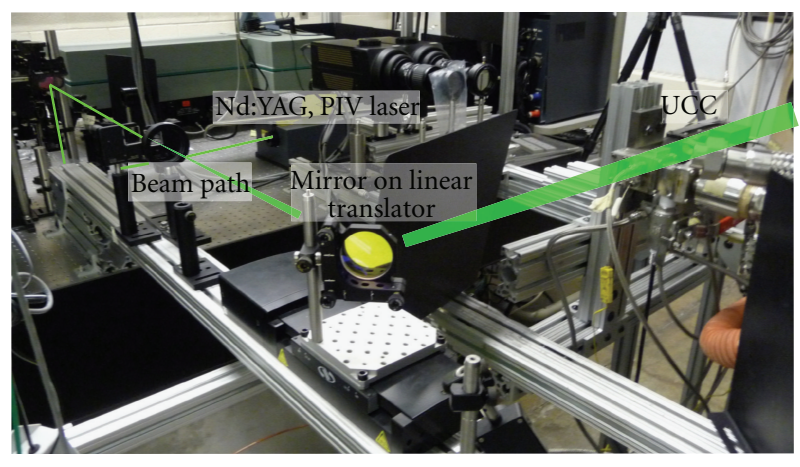

FIGURE 7: Optical path from laser to UCC sector rig with laser path drawn in green.
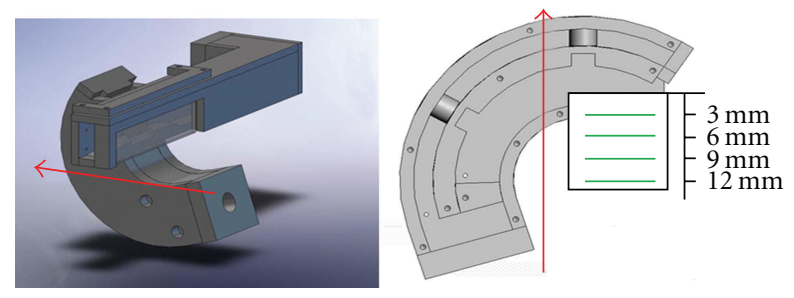

Figure 8: Positions of the four experimental planes within the UCC main flow channel for the curved circumferential section. Measurement planes at $3 \mathrm{~mm}, 6 \mathrm{~mm}, 9 \mathrm{~mm}$, and $12 \mathrm{~mm}$ (not drawn to scale) are shown on the right. The section is rotated, as indicated by the arrow, to show two views.

The air supply system was more stable overall at higher mass flow rates, Figure 10. Factoring in the $\pm 1 \%$ accuracy of the hydrogen mass flow controllers and the variability in equivalence ratio are shown in Table 3.

Statistical accuracies were calculated based on sampling variance, the number of samples, and the confidence interval for each point over each data set. Regions with higher turbulence exhibited higher overall variance. Variances attributed

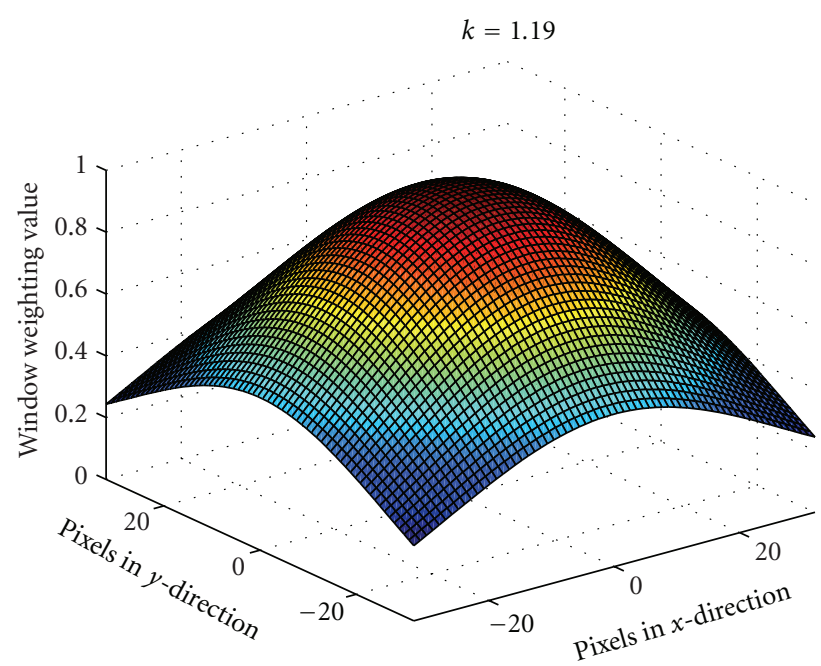

Figure 9: Weighting coefficients used with window function.

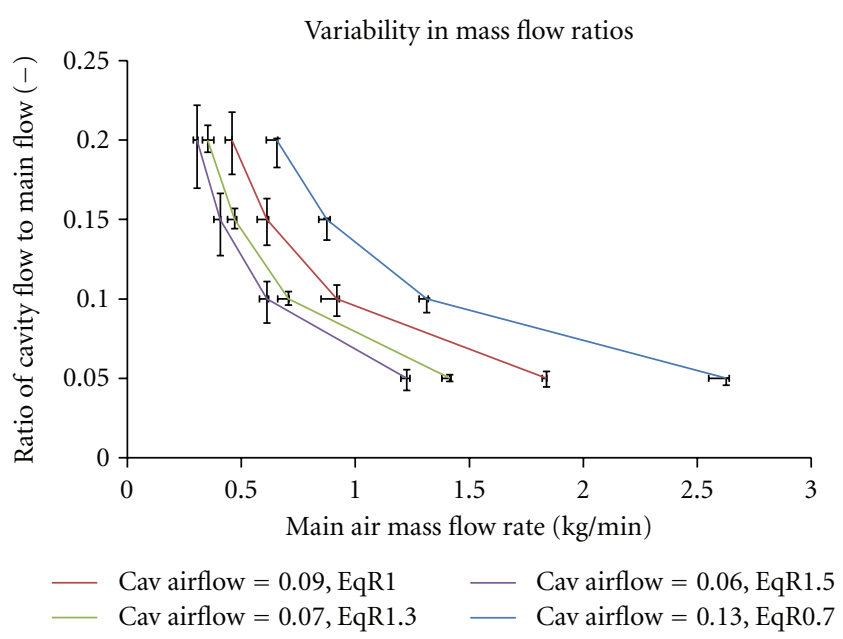

FIGURE 10: Variability in air mass flow rate combinations yielding different equivalence ratios. 


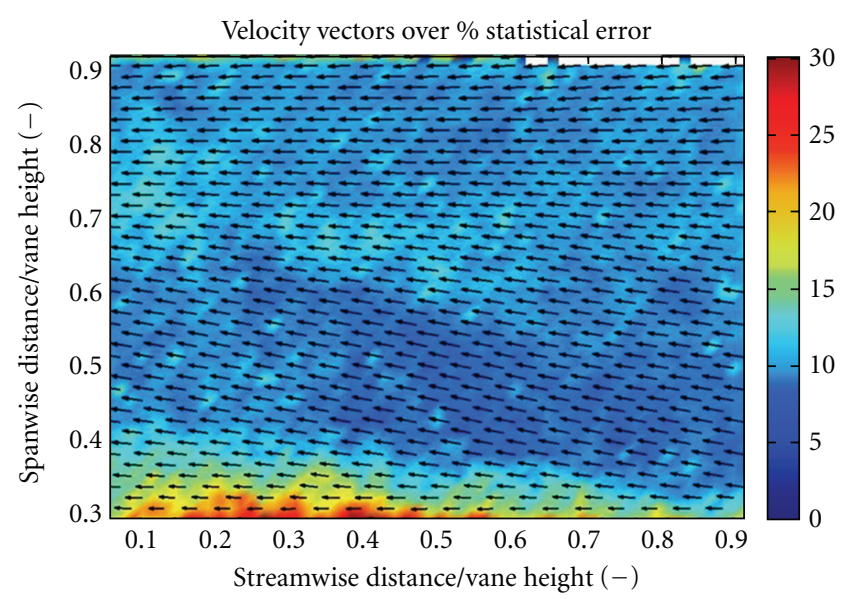

Figure 11: Velocity vectors superimposed on a color map of the $\%$ statistical error at $95 \%$ confidence.

TABLE 3: Observed variability in equivalence ratio.

\begin{tabular}{lcc}
\hline Equivalence ratio & Lower bounds & Upper bounds \\
\hline 0.7 & 0.68 & 0.77 \\
1.0 & 0.92 & 1.12 \\
1.3 & 1.24 & 1.35 \\
1.5 & 1.37 & 1.77 \\
\hline
\end{tabular}

to systemic and procedural influences were minimized in the experimental capture of data as much as possible. For example, areas exhibiting spurious vectors due to laser reflections or uneven particle distributions were removed using the methods described here.

Maintaining accuracy of the measured data proved to be particularly critical for derived values. Position accuracy affected velocity accuracies. The accuracy of the velocity vectors, in turn, define the accuracy the data can accurately represent the vorticity. In each step of the data reduction, the standard error is used to determine the accuracy of the data represented and the parameters of interest calculated.

A more complete discussion of the data capture and issues associated can be found in [9]. Figure 11 shows a representative sample of velocity error using a $95 \%$ confidence limit.

As described in Section 2 and shown in Figure 8, data was taken over four successive planes parallel to the main flow channel and the cavity flow channel. The planes are each approximately $20 \mathrm{~mm}$ high (cavity flow direction) and $30 \mathrm{~mm}$ across (main flow direction) and situated directly above (perpendicular to) the radial vane cavity (RVC). The RVC blocks the laser sheet illuminating the experimental plane, so the bottoms of the plots are actually just above the RVC.

The image pairs are converted into matrices of velocity data through the PIV processing described in Section 3 and then analyzed to graphically display average velocity, vorticity, and turbulence intensity. All data was taken at the maximum system data acquisition rate of $7.4 \mathrm{~Hz}$ with varying pulse delays based on the estimated main flow velocity. The velocity data is presented as a vector map overlaid on a color map representing mean velocity magnitude. The vorticity maps show areas of local flow rotation. The vorticity calculation involves comparing each velocity vector to the four adjacent vectors to determine any local rotation. As there should be zero global in the flow rotation, nonzero values in time-averaged vorticity maps can indicate quasistable eddies. Turbulence intensity was calculated in a slightly nonstandard form. Generally calculated as the standard deviation of a component velocity normalized by the component mean, turbulence intensity results presented in this paper are normalized by the total (not component) mean velocity. The bulk spanwise velocity was proximal to zero and overestimated the spanwise turbulence influence when normalized with the component velocity. The spanwise component of turbulence intensity was of primary interest. Small variations in a denominator close to zero introduce a unnecessary exaggeration of the calculated result. In normalizing by the total local velocity mean, streamwise, and spanwise turbulence intensity values can be more accurately compared from one data set to the next giving a much more meaning comparison. The equations used for velocity, vorticity, and turbulence intensity calculations are shown below.

Mean velocity for $u$ and $v$ components:

$$
\mu_{u}=\frac{1}{N} \sum_{i=1}^{N} U \text { or } V
$$

vorticity $(m, n)$ :

$\frac{V_{y}(m+1, n)-V_{y}(m-1, n)}{\Delta x}-\frac{V_{x}(m, n+1)-V_{x}(m, n-1)}{\Delta y}$,

streamwise turbulence intensity:

$$
\mathrm{TI}_{u}=\frac{\sigma_{u}}{\sqrt{\mu_{u}^{2}+\mu_{v}^{2}}}
$$

spanwise turbulence intensity:

$$
\mathrm{TI}_{v}=\frac{\sigma_{v}}{\sqrt{\mu_{u}^{2}+\mu_{v}^{2}}}
$$

RMS-direction turbulence intensity:

$$
\mathrm{TI}_{\mathrm{rms}}=\frac{\sqrt{\sigma_{u}^{2}+\sigma_{v}^{2}}}{\sqrt{\mu_{u}^{2}+\mu_{v}^{2}}} .
$$

In (2)-(6), $\mu$ is the component mean velocity in the streamwise $(u)$ or spanwise $(v)$ directions, $(m, n)$ is the location of the center of the interrogation region in Cartesian coordinates, $\sigma$ is the standard deviation of the velocity measurements for that interrogation region over all image pairs, and the subscript "rms" stands for root-mean-square. 


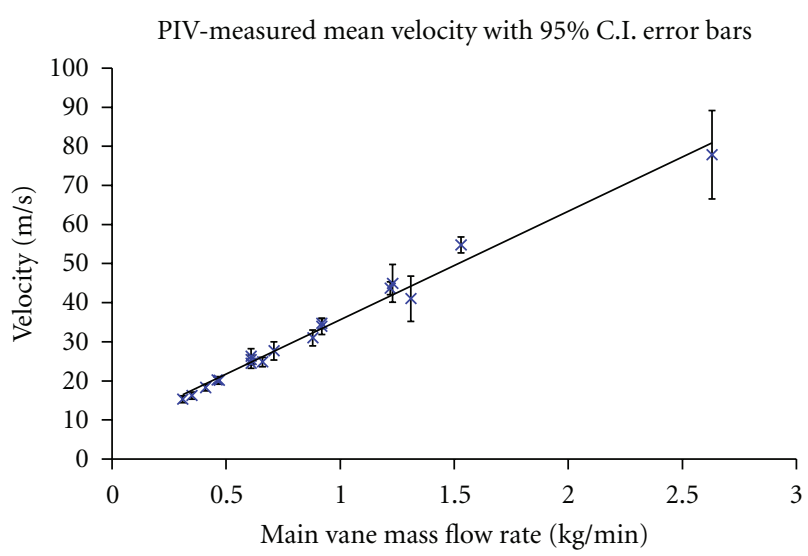

Figure 12: Mean velocity in the main channel measured at $75 \%$ of the main channel depth away from the cross flow for experimental plane three ( $9 \mathrm{~mm}$ from the combustion cavity).

\section{Results}

4.1. Velocity Measurements. Velocity was measured as a function of mass flow rate set by the main flow and cavity flow controllers. Generally speaking, one would expect velocity magnitude in the main channel to be directly proportional to mass flow as long as the equivalence ratio was held constant. However, it was still necessary to check the proportionality because the flow is complicated by the presence of two inlets and two exits. Indeed, this linear trend was observed, with a typical plot shown in Figure 12, as long as the mass flow ratio and equivalence ratio were maintained constant.

Next, the mean streamwise and spanwise velocity components throughout the depth of the main channel are examined. The mean velocity over the entire experimental plane tended to remain relatively constant throughout the depth of the main channel as shown in Figure 13 except over experimental plane 1 ( $3.0 \mathrm{~mm}$ from the cavity channel), very near the cross flow of the cavity channel. Data from both the straight and the curved cavity channels showed a decrease in streamwise velocity near the cross flow of the cavity channel. The most probable explanation for this velocity decrease is some of the main air is flowing out into the cavity channel.

The average spanwise velocity for each experimental plane decreased nearly linearly with distance from the cross flow of the cavity channel (Figure 14). As the channel upstream of the test section is constant and straight, a zero mean spanwise velocity component is expected. Two possible causes of the positive spanwise increase are (1) the radial vane just upstream of the test section could divert the flow upward, and (2) the flow nearest the cross flow of the cavity channel is being sucked into the cavity channel. Examining the first proposed cause, the profile of the radial vane's leading edge is constant throughout the depth of the main channel, meaning any contribution to the spanwise velocity component is expected to be constant throughout the depth of the main channel. Therefore, the spanwise velocity increase is not likely caused by the radial vane. The second proposed cause, that some of the main airflow is exiting the main channel and flowing into the cavity channel, is more likely because it would create an effect proportional to the main air proximity to the cavity channel.

The averaged velocity data allows comparison of entire data sets, but masks regional variation within the experimental plane. Figure 15 shows mean velocity vectors plotted over color maps of velocity magnitude for the experimental plane closest to the cavity channel (plane 1, 3.0 mm from the cavity channel) and for a plane farther from the cavity flow (plane 3, $9.0 \mathrm{~mm}$ from the cavity channel). Within the top half of the experimental plane for both planes, the vectors are nearly entirely in the streamwise direction, but the magnitude decreases approximately $10 \mathrm{~m} / \mathrm{s}$ by the time it exits the experimental plane. If hot combustion products and reacting flow from the cavity channel were entering the main channel, both the influx of mass and the increase in temperature would result in an increase in the velocity from right to left. The observed decrease in velocity implies more airflow is moving from the main channel into the cavity channel than the reverse. This trend is clearer for the measurement plane nearest the cavity flow. A second trend evident from this comparison is the component in the direction of the cavity flow, which corresponds to the upward direction for this figure, is larger for the plane near the cavity. These two aspects of the flow fields were analyzed more thoroughly by considering subsets of the planar velocity data.

In Figure 15(a), the vertical line on the right (near the 0.8 position) marks the axial location of the leading edge of the radial vane cavity (RVC), and the vertical line on the left (near 0.2) marks the axial position of the RVC's trailing edge. These vertical lines mark the locations from which the velocity profiles are plotted in Figure 16. In the UCC sector rig, the circumferential flow channel connects to the main flow channel just over the RVC. In order to study the velocity profile over the RVC, the mean flow velocity over the depth of the main flow channel is plotted as a function of height above the RVC.

The results in Figures 16 and 17 support the supposition total flow velocity in the UCC main channel decreases over the RVC with the straight circumferential flow channel and increases with the curved circumferential channel. The curves in the left of each figure depict the velocity profile along the height of the main channel at the axial position of the leading and trailing edges of the RVC. The red line (square markers) shows the difference between the velocity profiles (top axis). This difference is negative for the straight section (Figure 16) and positive for the curved section (Figure 17). The flow conditions in these figures are $1.5 \mathrm{~kg} / \mathrm{min}$ main and $0.15 \mathrm{~kg} / \mathrm{min}$ circumferential and an equivalence ratio of 1.0. The main channel RMS velocity decreased by an average of $1.5 \mathrm{~m} / \mathrm{s}(2.8 \%)$ with the straight circumferential channel whereas the main channel RMS velocity increased by an average of $2.9 \mathrm{~m} / \mathrm{s}$ (5.3\%) with the curved circumferential channel.

4.2. Vorticity Measurements. As the airflow moves over the radial vane cavity (RVC) from right to left, flow rotation is expected to be counterclockwise near the bottom of the experimental plane and approximately zero elsewhere. For 

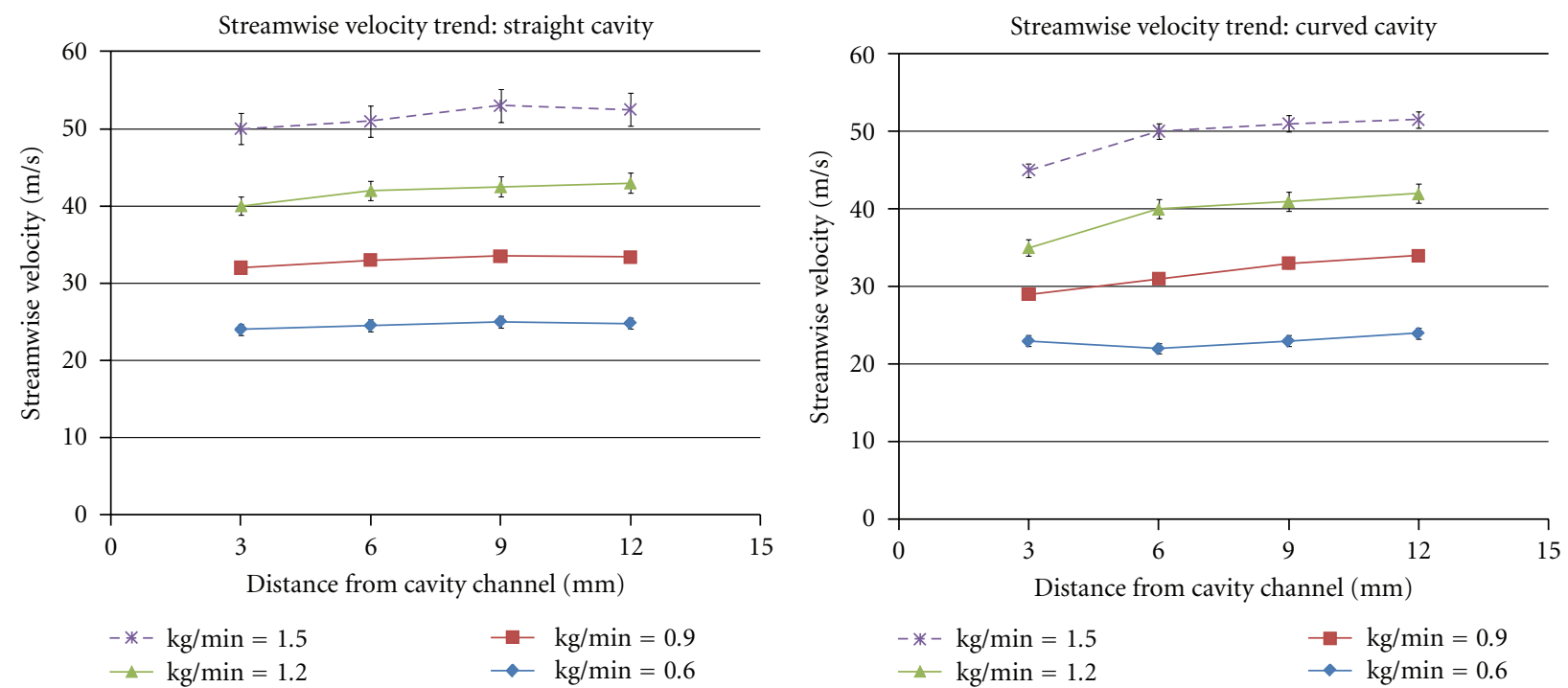

FIgURE 13: Mean streamwise (U) velocity as a function of depth within the main channel.
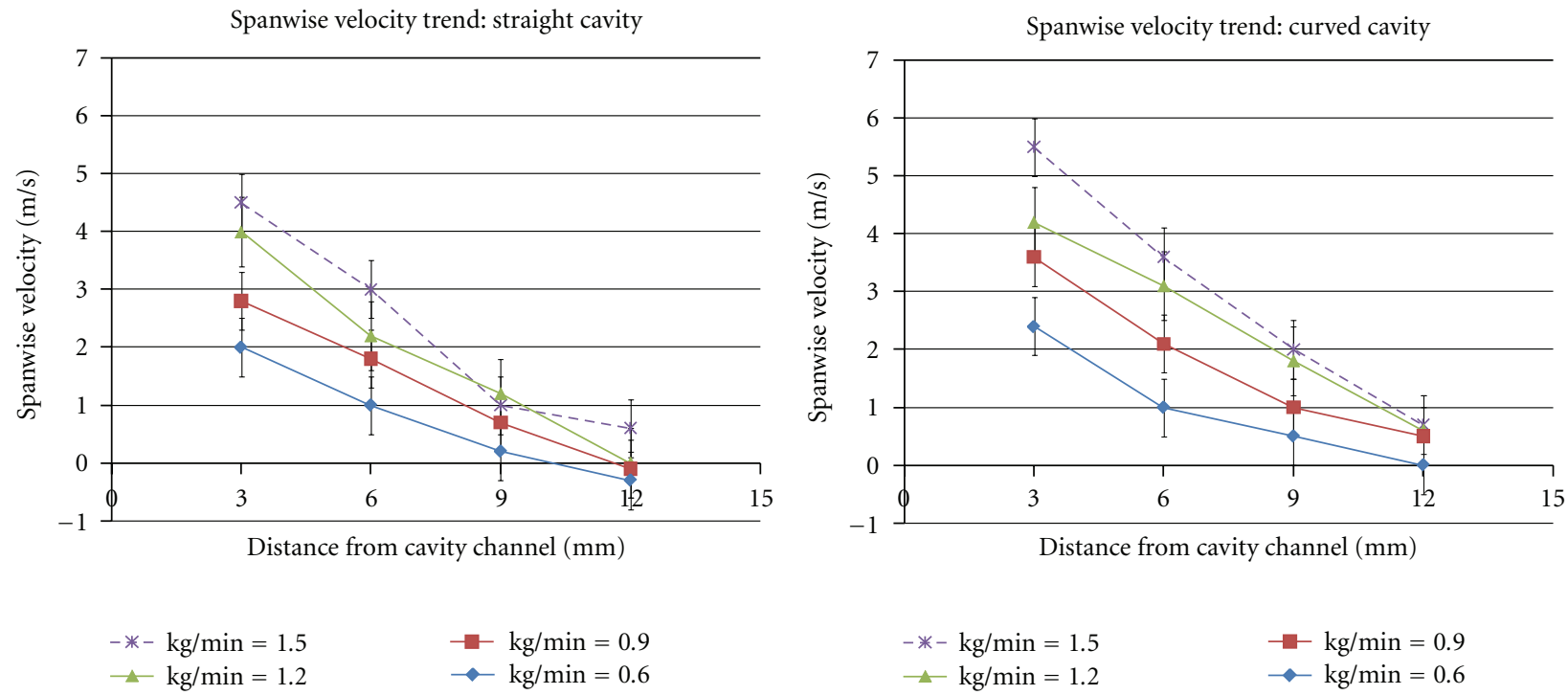

FIGURE 14: Mean spanwise (U) velocity as a function of depth within the main channel.

in-plane vorticity, defined in (3), clockwise flow rotation is defined as negative, and counterclockwise is positive. As expected, mean vorticity values were measured near zero, except just above the RVC. The positive vorticity values, indicating counterclockwise rotation is evident at the bottom of the vorticity plots in Figures 18 and 19.

Positive vorticity values above the cavity were expected. Interestingly, the flow rotation above the RVC increased with distance away from the cavity channel. Figure 18 shows data from the second experimental plane on the left, and Figure 19 shows data from the fourth experimental plane on the right. The color maps on top shows the region of high vorticity above the RVC increasing from plane two to four (moving away from the circumferential flow channel). The histograms also show more interrogation regions with high positive vorticity exist in the data from experimental plane four. This increase in vorticity over the RVC is likely caused by the angle of the cavity within the radial vane. The leading edge of the cavity is farther upstream on the circumferential channel (plane one) and farther downstream near the optical window (plane four). A portion of the vorticity induced by the leading edge of the cavity in plane one is likely to propagate into the second plane, which will then grow and induce increasing amounts of flow rotation in the third and fourth planes due to the angle of the cavity's leading edge.

4.3. Turbulence Intensity Measurements. As shown in (4)(6), turbulence intensity is measured as the local standard 


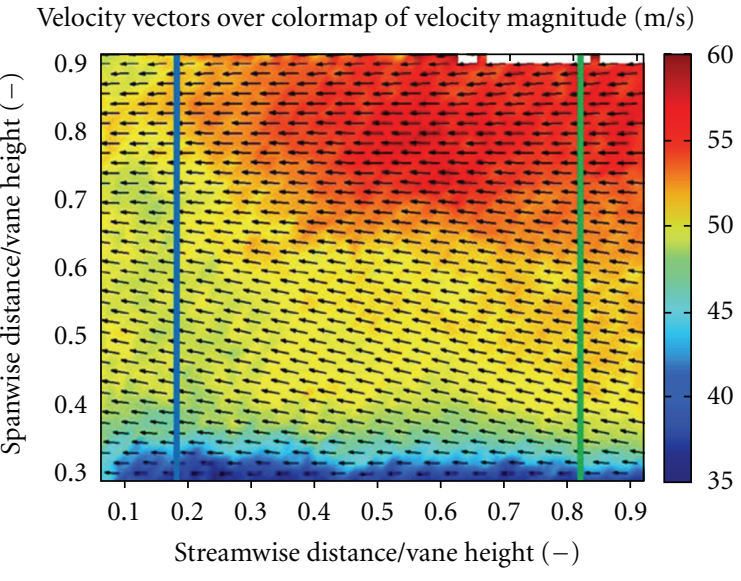

(a)

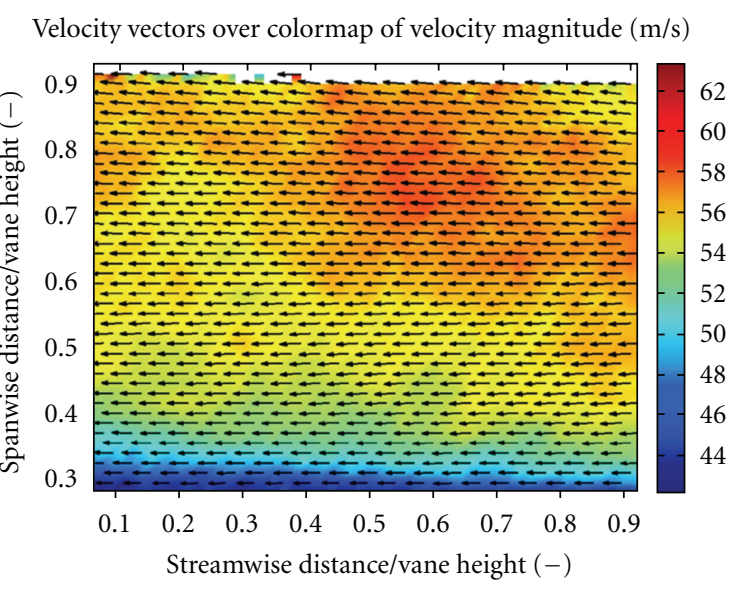

(b)

FIGURE 15: Velocity vectors with magnitude as background color for experimental planes (a) near the cavity channel (3 mm plane) and (b) far from the cavity channel ( $9 \mathrm{~mm}$ plane). Data is shown for the straight channel, with the main flow of $1.53 \mathrm{~kg} / \mathrm{s}$ and a cavity flow of $0.15 \mathrm{~kg} / \mathrm{s}$. Vertical lines on (a) mark the position of leading (0.8) and trailing (0.2) edge of RVC axial position.

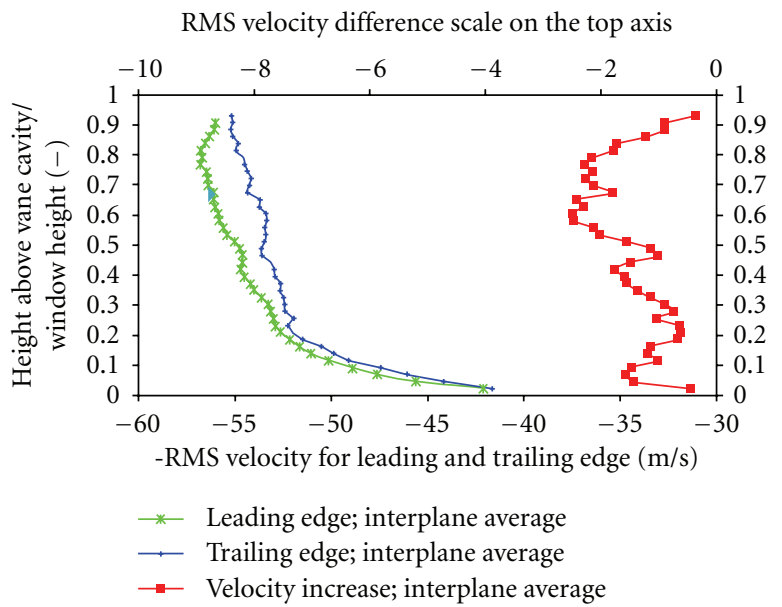

FIGURE 16: Velocity profile over RVC for straight configuration, $1.5 \mathrm{~kg} / \mathrm{min}$ main airflow.

deviation divided by the local mean value in the measured velocity over the total number of samples. Turbulence intensity gives a relative measure of the velocity variation in terms of a percent of the flow velocity. Averaging all collected data, RMS mean turbulence intensity in the UCC was measured at $14.6 \%$ with the straight cavity channel configuration and $21.3 \%$ with the curved cavity channel configuration. These averaged values can be stratified according to the experimental plane over which they were taken as shown in Figure 20.

As experimental plane 1 was closest to the cross-flow of the cavity channel, higher overall turbulence was expected. Further, higher overall turbulence was expected with the UCC configured with the curved cavity channel, because the exit of the curved cavity channel was smaller than the inlet resulting in forced mixing of the cavity channel flow into the main flow. The reverse trend observed with increasing
RMS velocity difference scale on the top axis

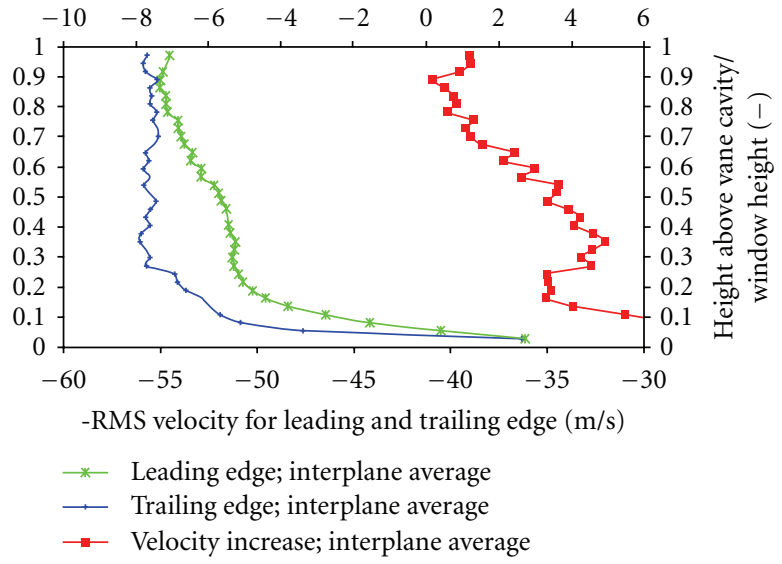

FIGURE 17: Velocity profile over RVC for curved (right) configuration, $1.5 \mathrm{~kg} / \mathrm{min}$ main airflow.

turbulence intensity levels from experimental planes three and four with the UCC configured in the curved cavity channel is not easily explained and is likely caused by complex flow.

Further examining the turbulence intensity within the experimental planes, certain regions exhibited patterns only in the streamwise or spanwise flow directions. In Figures 21 and 22, the vertical axis and color of the contour represents turbulence intensity (as a ration instead of as a percentage).

Streamwise turbulence intensity was largely constant over experimental planes one through three, but increased at plane four (Figure 21). This increase is expected to have resulted from boundary layer effects near the window. Throughout the thickness of the UCC main channel, streamwise turbulence intensity sharply increased near the bottom of the experimental plane just above the RVC. 


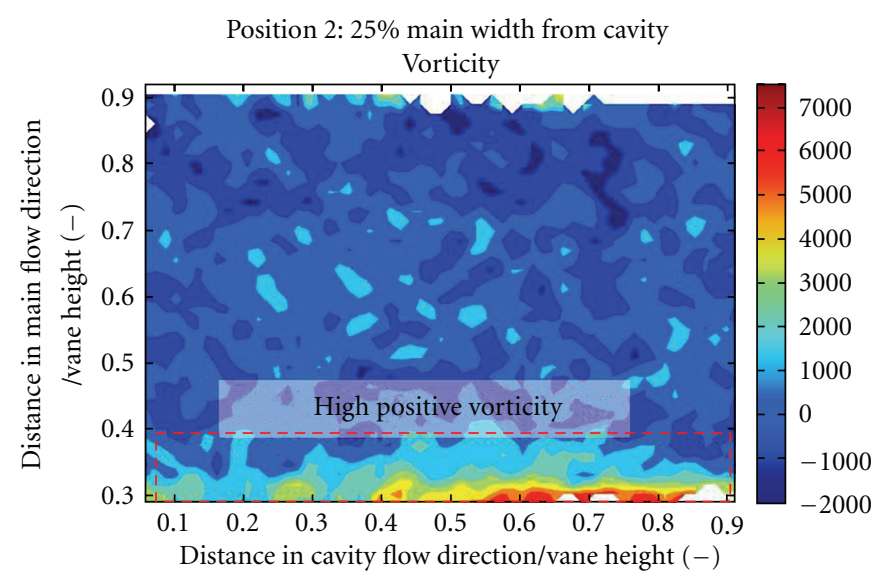

(a)

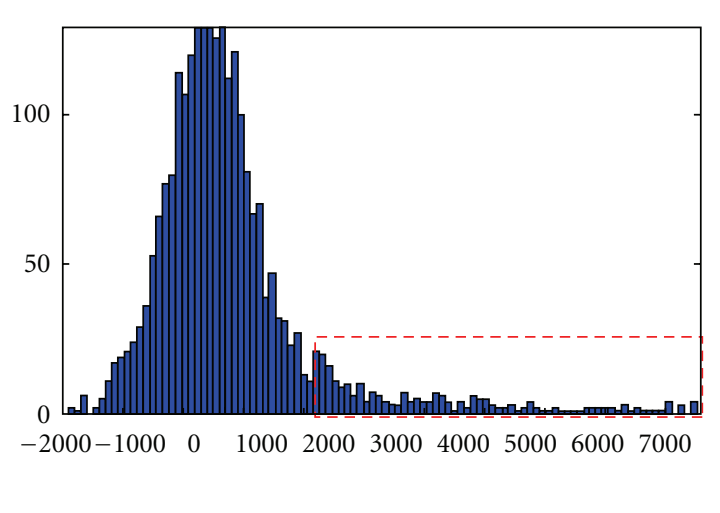

(b)

FIgURE 18: Vorticity plot showing counterclockwise flow rotation over the RVC (a); vorticity histograms (b), Position 2, 6 mm from combustion chamber.

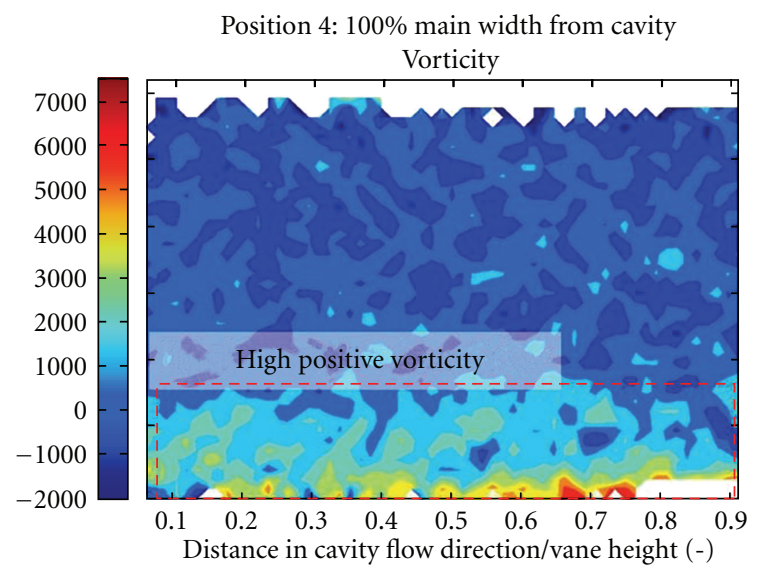

(a)

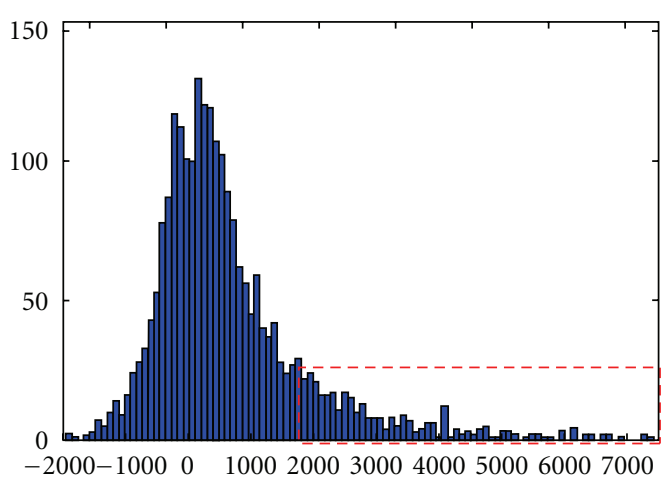

(b)

FIGURE 19: Vorticity plot showing counterclockwise flow rotation over the RVC (a); vorticity histograms (b), Position 4, 12 mm from combustion chamber.

The spanwise turbulence intensity exhibited less predictable behavior (Figure 22). Like the streamwise turbulence, the spanwise peaks just above the RVC and drops off quickly moving upward. However, unlike the streamwise turbulence which was fairly constant in the upper half of the experimental plane, spanwise turbulence seems to step up from less than $10 \%$ in the bottom half of the experimental plane to nearly $15 \%$ in the top half.

This turbulence increase in the upper half of the main channel is potentially the result of flow interaction between the circumferential flow channel and the upper wall of the main channel. Observed in the first experimental plane only, this flow behavior occurred at all equivalence ratios and mass flow ratios.

The final trend observed in the turbulence statistics was a dependency on velocity when the UCC was configured with the curved circumferential channel. As turbulence intensity is a measure of velocity variation relative to the bulk velocity, changing the bulk velocity is not expected to have a strong influence. If the overall turbulence level is at $10 \%(0.10$ in the figure) when the main airflow is $50 \mathrm{~m} / \mathrm{s}$, increasing the main airflow velocity to $100 \mathrm{~m} / \mathrm{s}$ is expected to result in similar relative turbulence levels of $10 \%$. This proportional consistency held true for data acquired with the UCC configured with the straight circumferential channel, but not with the curved circumferential channel.

Configured with the curved circumferential channel, both streamwise and spanwise turbulence intensity levels decreased with increasing main flow velocity. Figure 23 show overall turbulence levels averaged over all four experimental planes at each main airflow setting.

\section{Summary and Conclusion}

The flow fields inside the ultracompact combustor (UCC) over the radial vane cavity (RVC) were characterized using particle image velocimetry (PIV) at four equivalence ratios and at five ratios of main airflow to circumferential airflow 


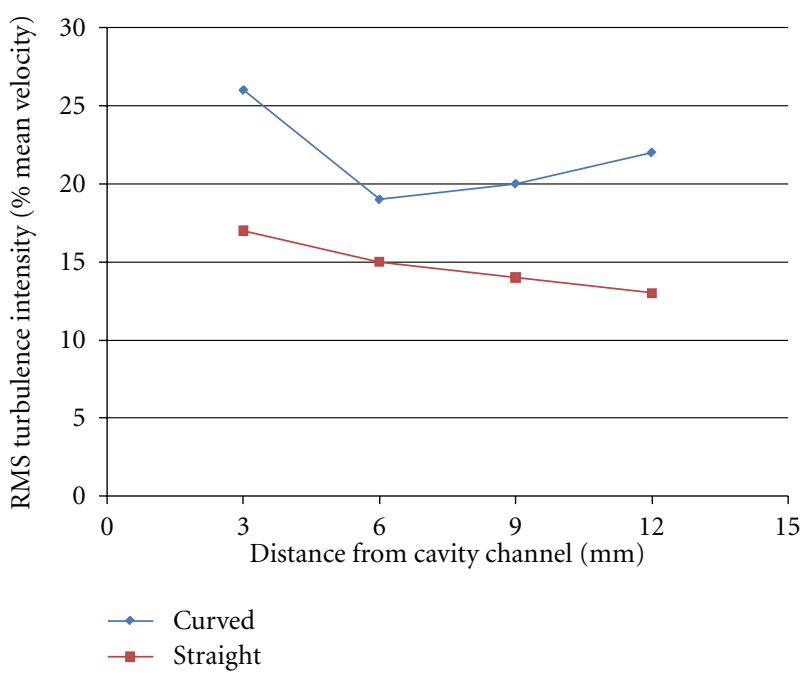

FIGURE 20: RMS average turbulence intensity over the depth of the main channel.

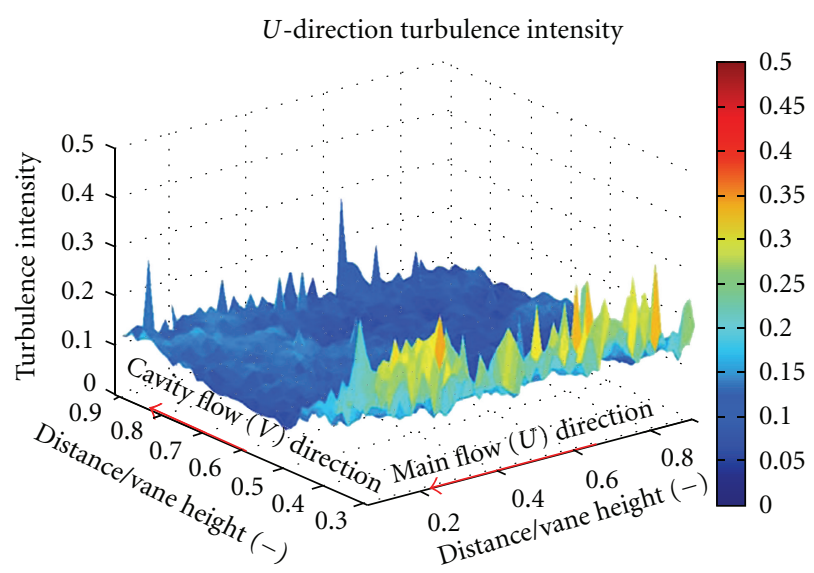

FIGURE 21: Streamwise turbulence intensity, equiv ratio $=1.0$, straight cavity vane configuration, main and cavity airflows: 0.9 and $0.09 \mathrm{~kg} / \mathrm{min}$.

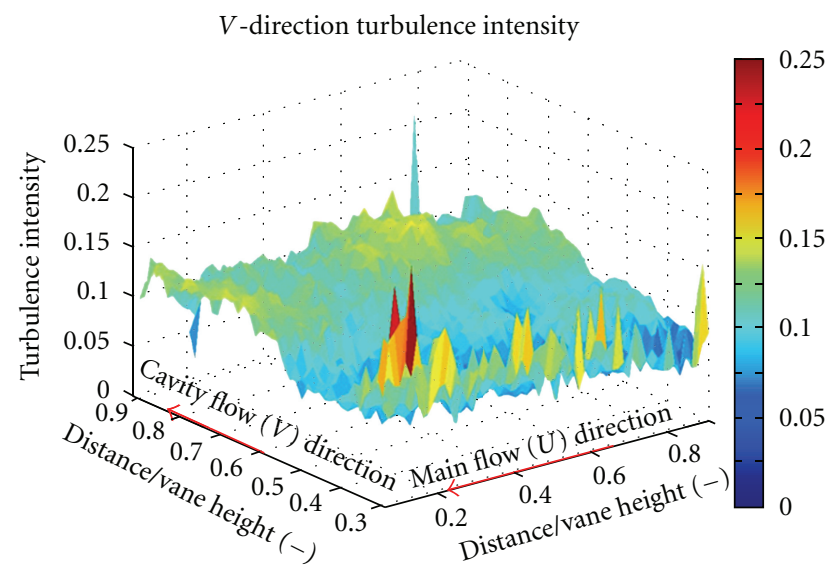

FIGURE 22: Spanwise turbulence intensity, equiv ratio $=1.0$, straight cavity vane configuration, main and cavity airflows: 0.9 and 0.09 $\mathrm{kg} / \mathrm{min}$.

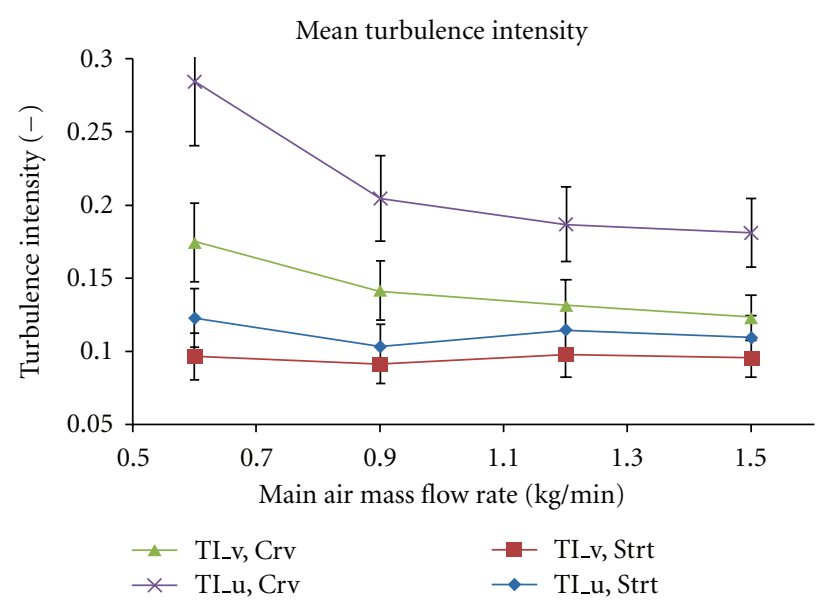

FIGURE 23: Planar-averaged spanwise turbulence intensity comparison of the straight and curved circumferential channels for an equivalence ratio $=1.0$. Main and cavity airflows were 0.9 and $0.09 \mathrm{~kg} / \mathrm{min}$, respectively.

with the straight circumferential flow channel. A second study was performed with the curved circumferential channel holding the equivalence ratio and the mass flow ratio constant at $\Phi=1.0$ and $10 \%$, respectively while increasing the flow rate magnitude. All PIV data was captured near the flow interaction region, within the main flow. The depth of the main channel was divided up into four experimental planes to compare the flow-field in the main channel near and far from the circumferential channel cross-flow.

Spanwise velocity and turbulence intensity in the main channel were strongly affected by the proximity to the circumferential channel. Spanwise velocity increased nearly linearly with proximity to the circumferential channel while both spanwise and streamwise components of turbulence intensity rose with proximity to the circumferential channel. Within each experimental plane, proportionally more of the turbulence appeared to be generated from the RVC compared to the cross flow interaction. The velocity profiles at two different axial positions (the leading and trailing edge of the RVC) were compared to estimate overall increase or decrease in mass flow within the main channel. The curved circumferential configuration led to an influx of combustion products into the main channel as evidenced by the increase in velocity across the RVC. This result is critical in that it lends support to the idea the UCC design will enhance mixing by less dense combustion products toward the centerline of a turbine.

The RVC was shown to create strong vorticity throughout the depth of the main flow channel supporting a recirculation zone for mixing the exhaust from the circumferential channel back into the axial flow. The increase in flow rotation away from the circumferential channel is likely the result of the angled leading and trailing edges of the RVC. The shape of the cavity in the RVC is one of the primary design variables needing optimized to develop the UCC concept into a usable main combustor or interturbine burner.

The results of this study validate previous work identifying the airfoil shape and cavity in the vane as key 
aspects of the UCC effectiveness. The enhanced mixing toward the centerline of the turbine indicates further design optimization into the height of the turbine vane is needed for this design, further increasing the potential benefit to an operational engine. The vorticity locations and intensity give rise to a path ahead for cavity design changes. By methodically approaching the resulting suggestions from this research to make design changes to the UCC combustion section, researchers will be closer to our overall engine goals of increased combustion efficiency, improved specific thrust and increased capability.

\section{Nomenclature}

$\Phi: \quad$ Equivalence ratio in circumferential flow path

GTE: Gas turbine engine

p: Pressure

PIV: Particle image velocimetry

$\dot{m}: \quad$ Mass flow rate

$\mu$ : Mean value

R: Gas constant

RVC: Radial vane cavity

$\sigma: \quad$ Standard deviation

T: Temperature

TI: Turbulence intensity

TVC: Trapped-vortex combustion

UCC: Ultracompact combustor

$\mathrm{V}$ : Velocity, or vorticity.

\section{Disclosure}

This material is declared a work of the U.S. Government and is not subject to copyright protection in the United States. Approved for public release; distribution is unlimited.

\section{Disclaimer}

The views expressed in this presentation are those of the authors and do not reflect the official policy or position of the United States Air Force, Department of Defense, or the U.S. Government.

\section{References}

[1] W. A. Sirignano and F. Liu, "Performance increases for gasturbine engines through combustion inside the turbine," Journal of Propulsion and Power, vol. 15, no. 1, pp. 111-118, 1999.

[2] J. Zelina, D. Shouse, and R. Hancock, "Ultra-compact combustors for advanced gas turbine engines," Tech. Rep. GT200453155, Power for Land, Sea, and Air, Vienna, Austria, 2004, ASME Turbo Expo.

[3] V. Katta, J. Zelina, and W. Roquemore, "Numerical studies on cavity-inside-cavity-supported flames in ultra compact combustors," Tech. Rep. GT2008-50853, Power for Land, Sea, and Air, Berlin, Germany, 2008, ASME Turbo Expo.

[4] P. J. Lakusta, Laser-induced fluorescence and performance analysis of the ultra-compact combustor, M.S. thesis, Graduate
School of Engineering and Management, Air Force Institute of Technology (AU), Wright-Patterson AFB OH, 2008, AFIT/GAE/ENY/08-J03.

[5] R. T. Greenwood and R. A. Anthenien, "Computational analysis of the ultra compact combustor," in Proceedings of the 43rd AIAA Aerospace Sciences Meeting and Exhibit, Reno, Nev, USA, 2005.

[6] J. D. Mattingly, Elements of Gas Turbine Propulsion, McGrawHill, 1996.

[7] J. Anisko and R. Anthenien, "Numerical investigation of cavity-vane interactions within the ultra compact combustor," in Proceedings of the 44th AIAA Aerospace Sciences Meeting and Exhibit, vol. 13, Reno, Nev, USA, 2006.

[8] W. S. Anderson, Design, construction, and validation of the AFIT small scale combustion facility and sectional model of the ultra-compact combustor, M.S. thesis, Graduate School of Engineering and Management, Air Force Institute of Technology (AU), Wright-Patterson AFB OH, 2007, AFIT/GAE/ ENY/07-M01.

[9] L. Thomas, Flow measurements using particle image velocimetry in the ultra compact combustor, M.S. thesis, Graduate School of Engineering and Management, Air Force Institute of Technology (AU), Wright-Patterson AFB OH, 2009, AFIT/GAE/ENY/09-D04.

[10] http://www.scitekconsultants.co.uk/7/Powder-Seeders.

[11] T. B. Hankins, Laser diagnostic system validation and ultracompact combustor characterization, M.S. thesis, Graduate School of Engineering and Management, Air Force Institute of Technology (AU), Wright-Patterson AFB OH, 2008, AFIT/ GAE/ENY/08-M14. 

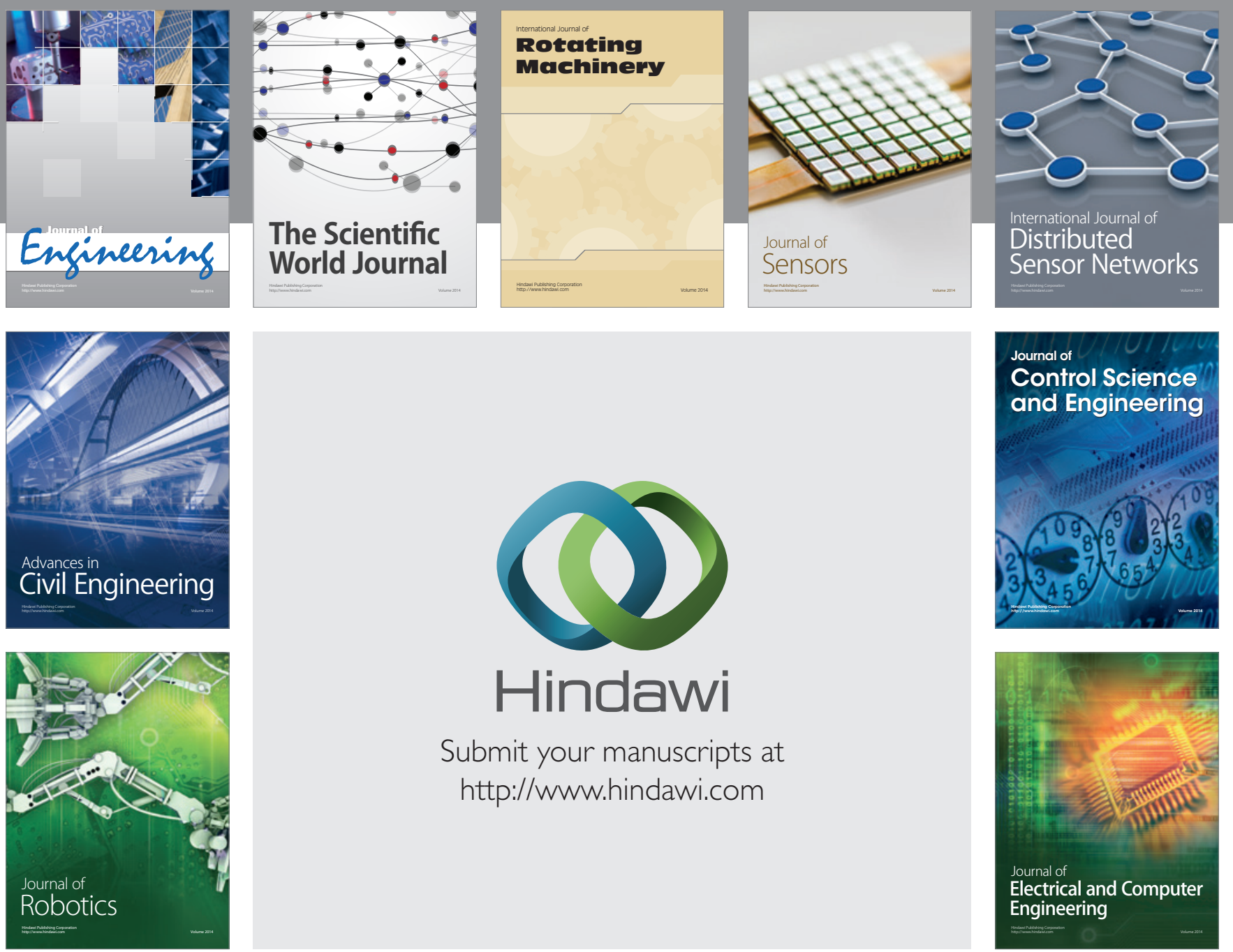

Submit your manuscripts at

http://www.hindawi.com
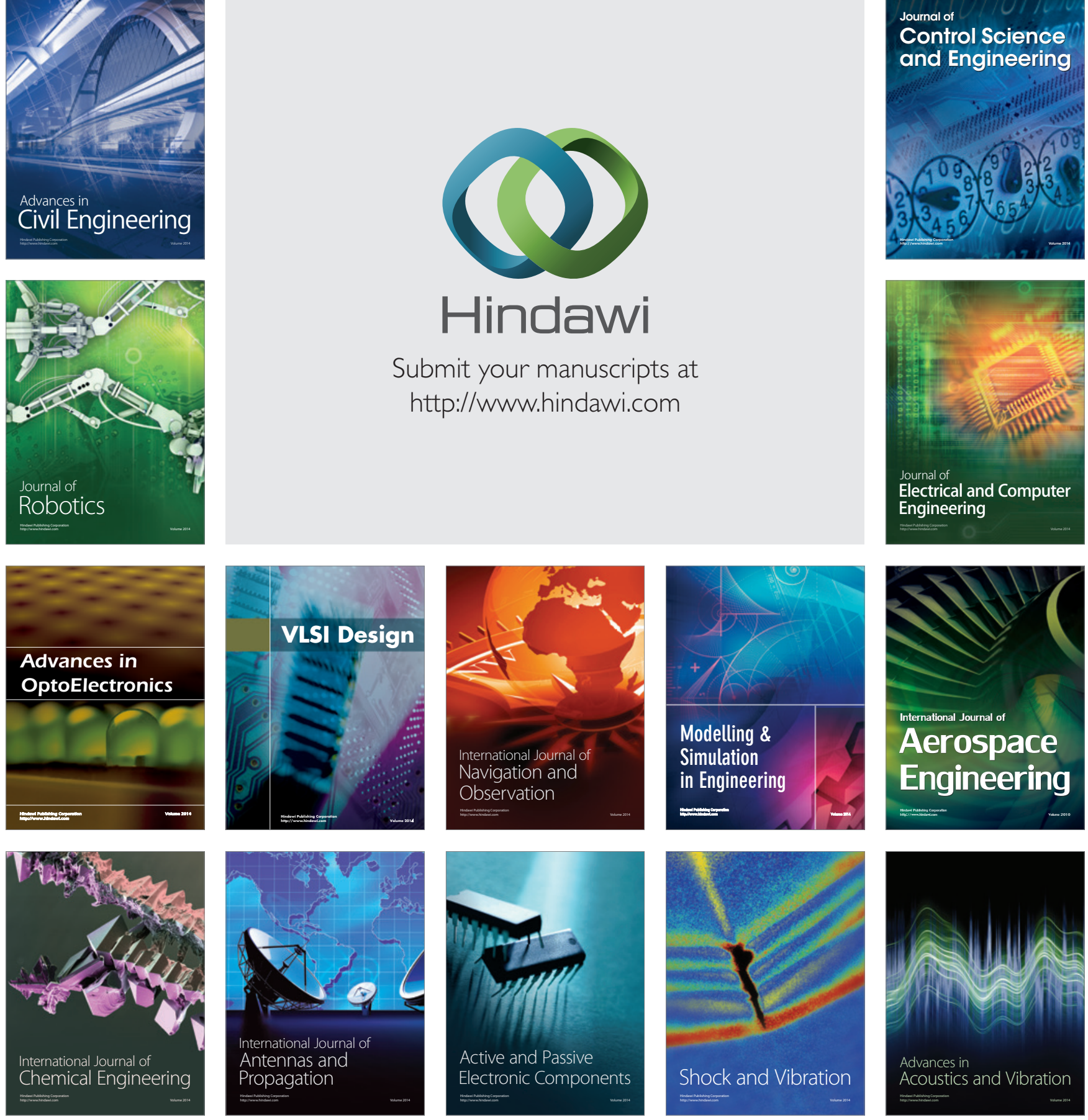